\title{
Reinvigorating Engagement and Collaboration through Interprofessional Education (RECIPE) in nursing and public health students
}

\author{
Yuan Zhang*1, Joel Tickner ${ }^{2}$ \\ ${ }^{1}$ Solomont School of Nursing, Zuckerberg College of Health Sciences, University of Massachusetts Lowell, Lowell, MA, United \\ States \\ ${ }^{2}$ Department of Public Health, Zuckerberg College of Health Sciences, University of Massachusetts Lowell, Lowell, MA, United \\ States
}

Received: May 7, 2018

Accepted: July 3, 2018

Online Published: July 9, 2018

DOI: $10.5430 /$ jnep.v8n12p15

URL: https://doi.org/10.5430/jnep.v8n12p15

\begin{abstract}
An interprofessional education (IPE) activity was piloted in an undergraduate Research Methods course with sophomore nursing and public health students. Students worked in small mixed groups mentored by course professors to critique a research article. The study aims to evaluate the IPE effectiveness in promoting students' readiness for IPE, and facilitating students' learning, critical thinking, and communication. Online survey with the Readiness for Interprofessional Learning Scale was administered to nursing and public health students pre- and post-IPE activity implementation. Nursing students' evaluation of the research critique assignment was compared with other nursing course sections. The study found that nursing students rated IPE better in facilitating critical thinking and communication than one previous class section without an IPE component. Students' qualitative comments suggested that future IPE will benefit from smaller groups, more even distribution of students from different disciplines, more shared faculty lectures, and integrating interactive group discussions.
\end{abstract}

Key Words: Interprofessional education, Readiness, Critical thinking, Communication, Teamwork

\section{INTRODUCTION}

Interprofessional education (IPE) refers to "occasions when two or more professions learn with, from and about each other to improve collaboration and the quality of care". ${ }^{[1]}$ IPE covers four competency domains including values and ethics, roles and responsibilities, interprofessional communication, and teamwork and team-based practice. ${ }^{[2]}$ IPE is particularly important for preparing health professions students since a collaborative team environment can improve patient care outcomes and health outcomes at a community level. ${ }^{[3]}$
However, most current university-based health education is delivered in a traditional single-discipline model, which is limited in its scope to prepare students with perspectives of other disciplines and opportunities for interdisciplinary collaborations. ${ }^{[4]}$ Although IPE is being progressively discussed for its benefits, implementation has many challenges and barriers. There remain large gaps relating to methods, theory, and context for IPE implementation in the current body of literature. ${ }^{[5]}$

Nursing represents the largest population of healthcare

\footnotetext{
*Correspondence: Yuan Zhang; Email: yuan_zhang@uml.edu; Address: Solomont School of Nursing, Zuckerberg College of Health Sciences, University of Massachusetts Lowell, Lowell, MA, United States.
} 
providers and plays a critical role in fostering communication and collaboration within healthcare teams. To ease the transition to interprofessional team-based model of practice, nursing students need to learn the value of teamwork and the principles of how to work with other health professionals. IPE could fulfill this need by providing nursing students opportunities to (1) experience the different values and ethics of other disciplines; (2) understand the distinct roles and responsibilities; (3) initiate and facilitate interprofessional communications; and (4) improve teamwork skills. ${ }^{[6]}$ Student engagement and motivation are a challenge for faculty in traditional lecture-oriented single-discipline courses. It is anticipated that IPE can promote active learning and stimulate knowledge sharing through continuous engagement and collaboration among students from multidisciplinary backgrounds. ${ }^{[7]}$

\section{Background for developing the IPE activity}

The Zuckerberg College of Health Sciences at the University of Massachusetts Lowell have four disciplines: Nursing, Public Health, Physical Therapy, and Biomedical \& Nutritional Sciences. A few years ago faculty teaching undergraduate Research Methods across the College convened to determine ways to better coordinate curricula. In this study, we piloted an IPE activity in an undergraduate Research Methods course with sophomore nursing and public health students. Research Methods is an ideal course for piloting IPE activities as it is one of the few courses that all students across the health sciences majors take in one form or another, is by its nature an interdisciplinary course, and provides a platform for early degree engagement in IPE in a topical area where approaches differ depending on profession (clinical vs. community). It is reasonable to explore the feasibility of offering one Research Methods course to undergraduates cross different health sciences disciplines.

Research in Nursing and Health Care (NURS.3010) is a three-credit, sophomore level course providing an overview of the research process to nursing students. This course was offered in three sections in fall 2015, with one section undergoing the pilot IPE activity. All three sections incorporate traditional lectures (one session/week) and student group work (one session/week) in the course design and evaluation. Research Methods in Public Health (PUBH.2060) is a three-credit, sophomore level course introducing students to the field of research in public health. This course was designed to support students in their ability to critique and communicate research results in a community decisionmaking setting. The course used a traditional lecture format (two sessions/week).

Nursing and public health research have overlapping objec- tives, but some different perspectives remain. Nurses use research to provide evidence-based care that promotes quality health outcomes for individuals. Public health professionals use research to prevent disease, and more importantly, promote community health from the perspective of populations, not individuals. Since these two courses target at same year (sophomore) students from nursing and public health majors with similar course objectives, we decided to promote student engagement and collaboration through incorporating an IPE activity - research critique. Research critique is a systematic way of objectively reviewing a piece of research to highlight its strengths and weaknesses, and its applicability to practice.

Previous studies have suggested the value of incorporating small-group activities to promote active learning. ${ }^{[5]}$ Guest lecture is valued in IPE due to providing students opportunities in learning about values and ethics, and roles and responsibilities with other professionals. ${ }^{[8]}$ Therefore, we designed this IPE activity through involving small mixed groups with both nursing and public health students mentored by faculty and offering faculty guest lectures to students in the other discipline. An ability to critically evaluate research studies is an important learning objective for both the nursing and public health research courses and was a similar learning activity previously designed and implemented in both courses. Therefore, the research critique activity provides a platform for implementing IPE with students from both majors.

In this study, we evaluated the effectiveness of the IPE activity in promoting nursing and public health students' readiness for interprofessional education covering the following areas: teamwork and collaboration, negative professional identity, positive professional identity, and role and responsibility. We also evaluated the effectiveness of the IPE activity in facilitating nursing students' learning, critical thinking, and communication skills.

\section{METHOD}

\subsection{Setting and subjects}

This IPE collaborative activity took place in fall 2015 with 8 nursing and 57 public health sophomore students at a public university in the northeast U.S. In fall 2015, all nursing students who enrolled in Research in Nursing and Health Care (NURS.3010, Section 203) and all Public Health students who enrolled in Research Methods in Public Health (PUBH.2060) were invited to participate in this IPE activity. Students were teamed into ten small mixed groups with about 6-7 students per group.

\subsection{IPE activity implementation}

In this IPE activity, nursing and public health students worked in small mixed groups mentored by two faculty mem- 
bers (one from Nursing and one from Public Health) to select and critique a primary research article that has relevance to either nursing or public health. The critique included a critical analysis of the problem statement, research questions and hypotheses, study design and methods, results, discussion and implications. Students were required to identify practical implications of the research from both the nursing and public health perspectives. Based on the analysis in the critique, students made recommendations for future nursing and public health research and practice to advance knowledge in both areas.

Throughout the semester, nursing and public health students worked together in five combined classes guided by two course professors on this critique assignment and gave ten group PowerPoint presentations in class at the end. The initial combined class included a common lecture with step-bystep guidance on how to critique a research study. Students were also required to work in their assigned small mixed groups after class to complete this assignment.

Along with the IPE activity, each faculty member guest lectured one class of the other course to introduce the research process in nursing or public health to students in the other major. Students were exposed to research perspectives from a different discipline and a different faculty member. Figure 1 described the IPE activity implementation process.

\subsection{Measurement of outcomes 2.3.1 Readiness for IPE}

Students' attitude to IPE was assessed with the modified Readiness for Interprofessional Learning Scale (RIPLS). ${ }^{[9]}$ The questionnaire has 19 items to examine students' attitude toward interprofessional learning. Each item is rated on a 5 -point Likert scale ( $1=$ strongly disagree; $2=$ disagree; $3=$ undecided; $4=$ agree; $5=$ strongly agree). The instrument has four subscales: teamwork and collaboration; negative professional identity (reverse coded); positive professional identity; and role and responsibility (reverse coded). The four subscales are aggregated to produce a total score ranging from 19 to 95 and a higher score indicates greater readiness for IPE. The reliability (Cronbach's alpha) of the subscales in the study sample averaged 0.80 . An open-ended question was included in the end asking students to provide further comments regarding their experience with IPE.

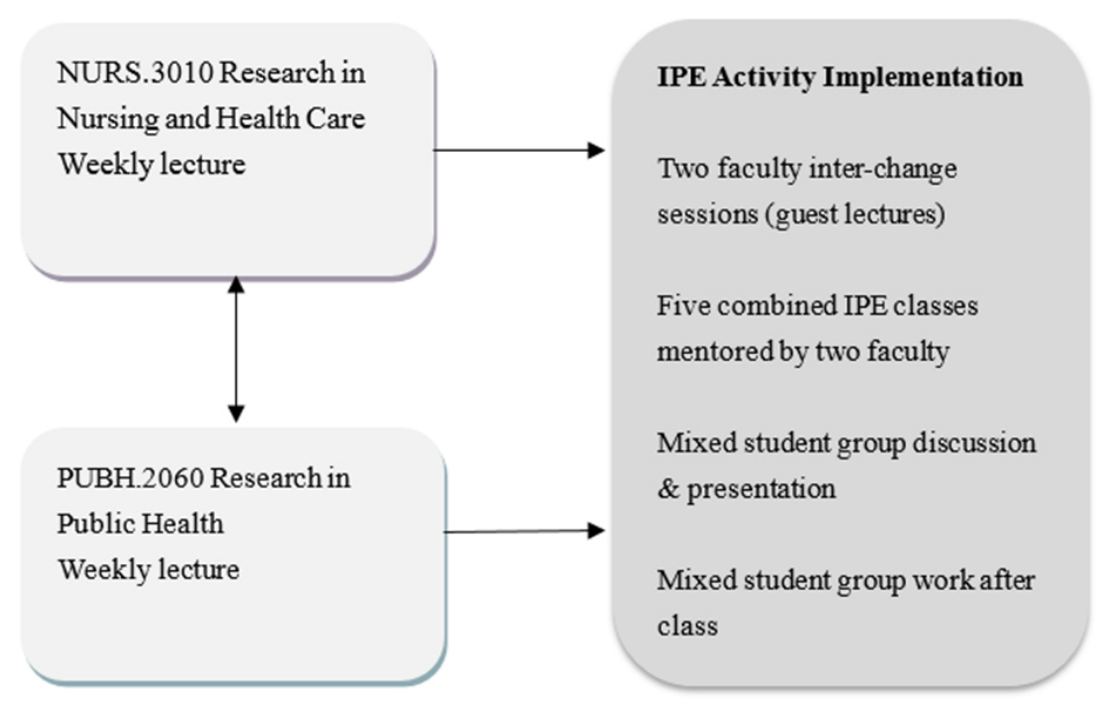

Figure 1. IPE Activity Implementation Diagram

\subsubsection{Assignment evaluation}

Nursing students were requested to evaluate this critique assignment as part of the course evaluation on a semester basis. Three items were used to evaluate how well this assignment (1) facilitated learning; (2) facilitated critical thinking skills; and (3) facilitated communication skills. Each item was rated on a 5 -point Likert scale $(1=$ poor; $2=$ fair; $3=$ good; 4 = very good; and $5=$ excellent) with a total score ranging from 3-15 and a higher score indicated better assignment evaluation. Since public health students did not have this assignment evaluation previously, this study only compared nursing students' assignment evaluation to other nursing course sections (fall 2015, other sections, $n=43$ ) and to the previous two semesters (spring 2015, $\mathrm{n}=18$; fall $2014, n=102$ ).

\subsection{Data collection}

The RIPLS was administered online through SurveyMonkey ${ }^{\circledR}$ to nursing and public health students one week pre- and one week post- the IPE activity imple- 
mentation. In-class announcements were made to students before distributing the online survey. Students were assured that the survey did not collect any personal identifier, participation was completely voluntary, and non-participation would not affect their course grade. Students received an invitation email with the survey link and two follow-up emails separately before and after the IPE activity in fall 2015. All emails were sent out directly through the office administrator at the School of Nursing. Informed consent signature was waived by the Institutional Review Board. The link to the survey started with an explanation of the study, which required students' reading and agreement before going to the survey questions.

Nursing students' evaluation of the research critique assignment was retrieved from the course evaluation database for the fall 2015, spring 2015, and fall 2014. The course evaluation survey was administered to nursing students who took the Research in Nursing and Health Care course on a semester basis through Survey Monkey. This study was reviewed and approved by the Institutional Review Board at the University of Massachusetts Lowell (No. 15-108).

\subsection{Data analysis}

All analyses were conducted using SPSS software 24.0. Scores of the RIPLS and the four subscales were compared pre- and post- the IPE activity using the independent samples $t$-test (comparing means of two or more independent groups). We did not use the paired samples $t$-test due to limited number of students $(n=16)$ who answered both pre- and post-IPE
RIPLS. Total score and scores of each item for nursing students' evaluation of the research critique assignment were compared between the IPE section separately with the fall 2015 other sections $(n=43)$, spring 2015 sections $(n=18)$, and fall 2014 sections $(n=102)$ using the independent samples $t$-test. ${ }^{[10]}$ Two-tail statistical significance was reported at $p<.05$. The open-ended question regarding students' expectations and experience on the interprofessional education were analyzed and summarized using content analysis. ${ }^{[11]}$

\section{RESULTS}

\subsection{Quantitative analyses}

There was a total of 8 nursing students and 57 public health students participating in this IPE activity, among whom, 35 students $(53.8 \%)$ completed the pre-IPE RIPLS, and 22 students $(33.8 \%)$ completed the post-IPE RIPLS. There were no significant differences reported pre-IPE compared to postIPE on the RIPLS total score and subscale scores (see Table $1)$.

Total score and scores of each item for nursing students' evaluation of the research critique assignment were compared, and no significant differences were reported between the IPE section with the fall 2015 other sections and the spring 2015 sections (see Table 2). When comparing the IPE section with the fall 2014 sections, students in the IPE section reported higher scores on facilitating critical thinking skills and facilitating communication skills, but no differences on the total score and facilitating learning score (see Table 2).

Table 1. Comparison of the RIPLS total score and subscale scores pre- and post-IPE activity implementation

\begin{tabular}{llll}
\hline & Pre-IPE (n= 35) & Post-IPE (n= 22) & Sig. \\
\hline RIPLS total score (19-95) & $77.8 \pm 8.8$ & $75.4 \pm 12.1$ & $p>.05$ \\
Teamwork \& Collaboration Subscale (9-45) & $40.2 \pm 5.1$ & $37.6 \pm 6.8$ & $p>.05$ \\
Negative Professional Identity Subscale (3-15) & $10.9 \pm 3.0$ & $11.4 \pm 2.4$ & $p>.05$ \\
Positive Professional Identity Subscale (5-25) & $21.3 \pm 3.6$ & $20.7 \pm 3.7$ & $p>.05$ \\
Role and Responsibility Subscale (2-10) & $5.8 \pm 1.2$ & $5.6 \pm 1.7$ & $p>.05$ \\
\hline
\end{tabular}

Table 2. Nursing students' evaluation of the research critique assignment

\begin{tabular}{|c|c|c|c|c|c|c|c|}
\hline & $\begin{array}{l}2015 \text { Fall IPE } \\
\text { Section }(n=8)\end{array}$ & $\begin{array}{l}2015 \text { Fall Other } \\
\text { Sections }(n=43)\end{array}$ & Sig. & $\begin{array}{l}\text { 2015 Spring } \\
(n=18)\end{array}$ & Sig. & $\begin{array}{l}2014 \text { Fall } \\
(n=102)\end{array}$ & Sig. \\
\hline Total score & $11.56 \pm 2.92$ & $10.00 \pm 3.10$ & $p>.05$ & $12.72 \pm 2.08$ & $p>.05$ & $10.25 \pm 3.43$ & $p>.05$ \\
\hline Facilitated learning & $3.78 \pm 1.09$ & $3.38 \pm 1.06$ & $p>.05$ & $4.17 \pm 0.76$ & $p>.05$ & $3.36 \pm 1.19$ & $p>.05$ \\
\hline Facilitated critical thinking skills & $3.89 \pm 0.93$ & $3.39 \pm 1.03$ & $p>.05$ & $4.17 \pm 0.76$ & $p>.05$ & $3.43 \pm 1.18$ & $p<.05$ \\
\hline Facilitated communication skills & $3.89 \pm 0.93$ & $3.51 \pm 1.05$ & $p>.05$ & $4.39 \pm 0.83$ & $p>.05$ & $3.48 \pm 1.22$ & $p<.05$ \\
\hline
\end{tabular}

\subsection{Qualitative analyses}

Students provided qualitative comments regarding interprofessional education and learning. Before implementing the IPE activity, students reported expectations towards IPE, "I think it would be a good idea to do collaborative projects with related professional fields so that we better understand each other's problems and what's important to each other's field. This may be working on research projects or seeing 
how each other's important issues mesh together and can be solved."

After implementing the IPE activity, students reported both positive and constructive feedback, "The class was very fun, but more shared lectures/more even distribution of students would obviously be better"; “... we didn't get to choose our groups, and some of the students were very difficult to work with"; “... a more learning and interactive group discussion may have yield better interprofessional learning than a group project"; "I think group size is important. ... an undergraduate level smaller groups would have worked better to get more benefits..."

\section{Discussion}

With increasing demands for better patient outcomes, interprofessional collaboration plays an important role in fostering safe, accessible, and high-quality care and improves public health outcomes. ${ }^{[3]}$ IPE is encouraged in preparing health professions students to create a collaborative team environment before entering practice. Our study piloted an IPE research critique activity implemented with nursing and public health undergraduate students in their sophomore Research Methods course. The IPE activity was designed to foster two-disciplinary collaborations, stimulate two-disciplinary understanding and knowledge sharing, and improve student engagement and active learning. ${ }^{[6]}$ It was anticipated that students in a new environment would be more likely to engage and collaborate actively in completing the project and meeting the course objective. IPE core competences of values and ethics, roles and responsibilities, communication, and teamwork ${ }^{[2]}$ were inherent to the group activity and group presentation. These competences are critical to any successful academic endeavor and it is important that our students practice these skills in a mentored setting early in their careers. Successful implementation of the IPE activity would inform our future process of integrating IPE into existing health education courses.

This study did not find the change of IPE readiness in total score and scores of each domain pre- and post-IPE activity implementation. This may be partially due to the small sample size, or because the instrument was not sensitive enough to report differences within short time periods. However, we found that nursing students rated the IPE activity better in facilitating their critical thinking and communication skills than one of the previous class sections without the IPE component. This finding was supported by the qualitative findings on students' comments to this IPE activity. In the past, IPE was primarily implemented with nursing, medical, and pharmacy students, ${ }^{[12-14]}$ with clinical-based IPE reported by students as most effective in enabling their ex-

Published by Sciedu Press change of perspectives and encouraging their feeling as part of a clinical team; while classroom-based IPE was reported by students as enabling them to know about teamwork, but not to experience it. ${ }^{[12]}$ However, our small mixed group activity provided nursing and public health students an opportunity to work and function as a team for completing an assignment and giving a group presentation, in which they practiced communication, teamwork, and collaborations. Also, in this process, students learned to divide roles and responsibilities among each group member to represent in the group presentation, in which, they gained experience in active learning and problem-solving.

Students' qualitative comments have provided us useful recommendations for future implementation of IPE into health education courses. Besides smaller groups and more even distribution of students from different disciplines, students would benefit more from increasing the number of shared faculty lectures and incorporating interactive group discussions into the IPE activity. Increasing the number of shared faculty lectures would help students to gain an understanding of other professional's roles in the healthcare team and process, which is one of the core competences of $\operatorname{IPE}^{[2]}$ and an essential part of the best practice models of IPE. ${ }^{[15]}$ Small group interaction, discussion, and collaborative learning have been favored as part of the IPE model to enhance student satisfaction with their learning experience. ${ }^{[13,16-18]}$ Previous studies reported that IPE initiative commonly includes group sizes of between 5 to 10 students to facilitated quality interactions. ${ }^{[19]}$ Group balance and stability, such as an equal mix of professionals and little "turnover" of group members (in terms of established members leaving and new ones joining), are also important for student interaction and learning process. ${ }^{[19]}$

\section{Challenges and limitations}

There were a number of challenges that we had encountered in implementing this IPE activity. On the one hand, the large number of students $(n=57)$ in public health and small number of students $(n=8)$ in nursing has resulted in the disproportionate distribution of students from both majors in each mixed group. This may have reduced the opportunity for public health students to interact more with and gain more in-depth knowledge from nursing students. As reflected in students' qualitative comments, they would benefit from more even distribution of students from both majors. On the other hand, the short-term IPE implementation (one semester), small sample size, and moderate response rate may limit the generalizability of the study findings. Nonetheless, our experience found that while there were clear benefits for students in terms of learning outcomes, implementation 
in practice of IPE program is a challenge given rigid program requirements, limited incentives for co-teaching, faculty overload, and scheduling challenges.

\section{Conclusion}

IPE promotes active learning and stimulates knowledge sharing through continuous engagement and collaboration among students from multidisciplinary backgrounds. This study involved the development and evaluation of an IPE activity implemented with nursing and public health students in their sophomore Research Methods course to foster engagement, understanding, communication, and collaboration across different disciplines. Students from nursing and public health worked together in small mixed groups mentored by course faculty to complete a research critique activity and give a group presentation in class. We learned from this study that future IPE implementation will benefit from smaller groups, more even distribution of students from different disciplines, more shared faculty lectures, and integrating interactive group discussions.

\section{CONFlicts OF InTEREST Disclosure}

The authors declare that there is no conflict of interest.

\section{REFERENCES}

[1] UK Center for Interprofessional Health Education. What is IPE? 2017 [cited 2017 November 25]. Available from: http: //www . uky . edu/cihe/content/what-ipe

[2] Interprofessional Education Collaborative. Core Competencies for Interprofessional Collaborative Practice 2011 [cited 2017 November 25]. Available from: https : //www . aamc.org/download/18 6750/data/core_competencies.pdf

[3] Reeves S, Perrier L, Goldman J, et al. Interprofessional education: Effects on professional practice and healthcare outcomes (update) The Cochrane database of systematic reviews. 2013; 3: CD002213.

[4] Lapkin S, Levett-Jones T, Gilligan C. A systematic review of the effectiveness of interprofessional education in health professional programs. Nurse Education Today. 2013; 33(2): 90-102. PMid:22196075 https://doi.org/10.1016/j.nedt.2011.11.006

[5] Olson R, Bialocerkowski A. Interprofessional education in allied health: A systematic review. Medical Education. 2014; 48(3): 23646. PMid:24528458 https : //doi .org/10.1111/medu. 12290

[6] Lennen N, Miller B. Introducing interprofessional education in nursing curricula. Teaching and Learning in Nursing. 2017; 12(1): 59-61. https://doi.org/10.1016/j.teln.2016.07.002

[7] Black EW, Blue AV, Davidson R, et al. Using team-based learning in a large interprofessional health science education experience. Journal of Interprofessional Education \& Practice. 2016; 5: 19-22. https://doi.org/10.1016/j.xjep.2016.09.002

[8] Davidson M, Smith RA, Dodd KJ, et al. Interprofessional prequalification clinical education: A systematic review. Australian Health Review. 2008; 32(1): 111-20. https ://doi.org/10.107 1/AH080111

[9] McFadyen AK, Webster VS, Maclaren WM. The test-retest reliability of a revised version of the Readiness for Interprofessional Learning Scale (RIPLS). Journal of Interprofessional Care. 2006; 20(6): 633-9. PMid:17095441 https://doi.org/10.1080/13561820600991 181

[10] Field AP. Discovering Statistics Using SPSS. London, England: SAGE Publications Ltd; 2013.
[11] Polit DF, Beck CT. Essentials of Nursing Research: Appraising Evidence for Nursing Practice. 8th ed. Philadelphia, PA: Lippincott Williams \& Wilkins; 2014.

[12] Morison S, Boohan M, Jenkins J, et al. Facilitating undergraduate interprofessional learning in healthcare: Comparing classroom and clinical learning for nursing and medical students. Learning in Health and Social Care. 2003; 2(2): 92-104. https://doi.org/10.104 6/j.1473-6861.2003.00043.x

[13] Curran VR, Sharpe D, Forristall J, et al. Student satisfaction and perceptions of small group process in case-based interprofessional learning. Medical Teacher. 2008; 30(4): 431-3. PMid:18569668 https://doi.org/10.1080/01421590802047323

[14] Cameron A, Ignjatovic M, Langlois S, et al. An interprofessional education session for first-year health science students. American Journal of Pharmaceutical Education. 2009; 73(4): 62. https : //doi.org/10.5688/aj730462

[15] Bridges DR, Davidson RA, Odegard PS, et al. Interprofessional collaboration: Three best practice models of interprofessional education. Medical Education Online. 2011; 16: 6035. PMid:21519399 https://doi.org/10.3402/meo.v16i0.6035

[16] Cusack T, O'Donoghue G. The introduction of an interprofessional education module: Students' perceptions. Quality in Primary Care. 2012; 20(3): 231-8. PMid:22828679

[17] Wamsley M, Staves J, Kroon L, et al. The impact of an interprofessional standardized patient exercise on attitudes toward working in interprofessional teams. Journal of Interprofessional Care. 2012; 26(1): 28-35. PMid:22233365 https ://doi .org/10.3109/1356 1820.2011.628425

[18] Hayashi T, Shinozaki H, Makino T, et al. Changes in attitudes toward interprofessional health care teams and education in the first- and third-year undergraduate students. Journal of Interprofessional Care. 2012; 26(2): 100-7. PMid:22251234 https ://doi.org/10.310 9/13561820.2011.644355

[19] Oandasan I, Reeves S. Key elements for interprofessional education Part 1: The learner, the educator and the learning context. Journal of Interprofessional Care. 2005; 19(Suppl 1): 21-38. PMid:16096143 https://doi.org/10.1080/13561820500083550 